\title{
A social constructionist approach to resilience for lesbian, gay, bisexual, transgender, intersex, queer and/or questioning academics and students in South African universities
}

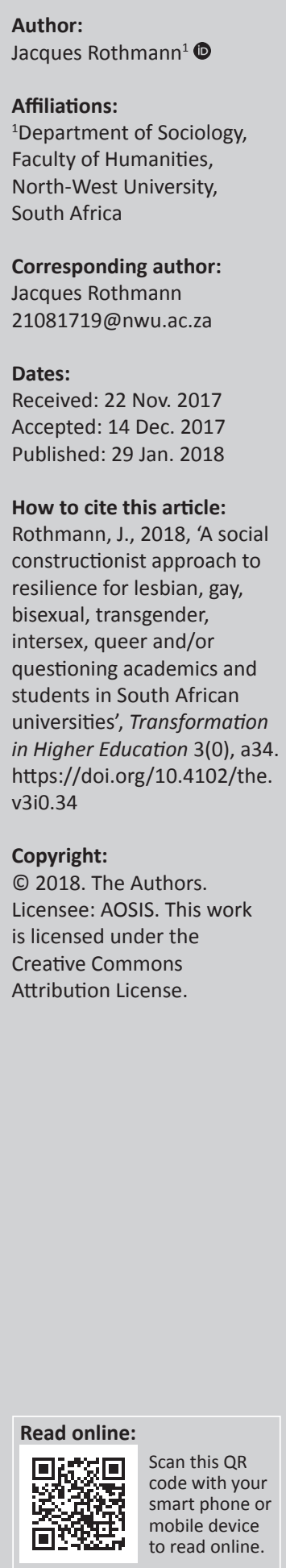

This article provides a theoretical contemplation on how reciprocation of an assimilationist, liberationist and/or transgressive approach by lesbian, gay, bisexual, transgender, intersex, queer and/or questioning (LGBTIQ+) individuals on university campuses may encourage transformation initiatives in South African universities. The author ascribe to the contributions of previous research studies on a social constructionist approach to resilience to debate how individuals potentially navigate the disparity between sexual structure and agency within their ideological and physical construction and enactment of their academic and student persona. A theoretical basis is provided for the influence of social resilience to emphasise the localised, intersectional and plural experiences of LGBTIQ+ individuals as opposed to a monolithic and universal 'either/or' account of their being solely docile victims or free agents in a heteronormative context.

\section{Introduction}

Cahill (2011:135) notes that sexual difference should not be viewed '...as a threat to be negotiated or a problem to be solved, but rather as the ... condition for the ... interactions through which the self develops'. This emphasises and contextualises the discussion that follows. Individuals internalise (whether implicitly or explicitly) and become stratified in the hierarchical gendered and sexual societal arrangements (Schippers 2016), depending on the culture which informs the gender and sexual order in a particular context. Much of the focus on homosexuality in a South African context emphasises the dualism between Constitutional protection of supposed sexual minorities and the actual experiences of acceptance (at best) and homophobia (at worst) in civil society (Bhana 2012; De Vos 2015; Wells \& Polders 2006). This disjuncture is mainly associated with the supposed 'un-African' label assigned to the secular import of the medicalised category of homosexuality (Francis \& Brown 2017), the prevailing centrality of patriarchy and heteronormativity in South Africa (Matthyse 2017) and the denial associated with the presence of gender and sexually diverse individuals in institutions (such as schools and universities) (Francis 2017a, 2017b). Heteronormativity as such may influence access to resources and interactions by sexual minorities (Kitzinger 2005), an arrangement favouring the construction and reinforcement of a heterosexual and/or homosexual binary logic, whereby '....institutionalised normative heterosexuality regulates those kept within its boundaries as well as marginalising and sanctioning those outside them' (Jackson 2006:105). This may create uncritical assumptions about heterosexuality as the norm, while rendering other forms of sexual identity as supposed subordinate 'others' (Rothmann \& Simmonds 2015) which potentially manifests in exclusion or even heterosexist and patriarchal violence (Bhana 2014; Msibi 2009).

I wish to theoretically engage the plausiblity of how self-identified LGBTIQ $+{ }^{1}$ people may attempt to 'grow into resilience' (Grace 2015) in order to reclaim their gendered and sexual identity as non-subordinated 'other' (Tong 2008) through an increased reflexive focus on the 'queering' of a supposed heteronormative academic context. In attempting this, one should

1.For the purpose of this article, the abbreviation ' $\mathrm{LGBTIQ}+$ ' is used as an inclusive concept referring to those individuals who self-identify as lesbian, gay, bisexual, transgender, intersex, queer and/or questioning as it relates to their sexual orientation and/or gender identity. Writing from a South African perspective, Msibi (2013) contends that regardless of the laudable transgressive properties of queer theory and the use of the concept 'queer', it is still informed by a Westernised history and understanding of sexual identity. As such, the acronym LGBTIQ+ is considered as more of an inclusive reference to those individuals who do not conform to heterosexual hegemony or heteronormative identity configurations which are informed by a cisgender model. Also, consider Fineman's (2014:307) argument in favour of augmenting the initial LGBT (Lesbian, Gay, Bisexual, and Transgender) acronym with new terms and categories in order to '...express diverse understandings of sexuality, gender, physical bodies, and evolving identities'. 
avoid opting for an 'either/or' approach which favours a binary logic (i.e. assimilation vs. liberationism or assimilation and/or liberationism vs. social constructionism). In ascribing to the underlying principles associated with these paradigms, one could posit initiatives and recommendations in favour of LGBTIQ+ people to access sources of social resilience and particular protective factors to transcend a view of South African universities as solely heteronormative and patriarchal spaces (Francis 2017b; Ungar 2004a, 2004b; Van den Berg 2016). By focusing on the theoretical contributions of scholars to social resilience, I consider whether these academics and students may be required to temporarily return to (or assimilate into) an initially homogeneous ethnic identity configuration as part of what could be considered as communal 'homosexual spaces' on campus to transcend their risk factors on their respective campuses through hidden resilience. In identifying with similar others, these individuals may, through a temporary or longitudinal assimilation, be granted the agency also to originate, formulate and redefine their own definitions of adversity, subjugation and/or resilience within this context and identity configuration along liberationist lines (Fineman 2014; Van den Berg 2016) to refute only having at-risk labels imposed on them by, among others, previous studies that may have (inadvertently) stigmatised sexual minorities as only passive and vulnerable within a heteronormative context.

Drawing on my own work (Rothmann 2012, 2017) and that of Francis (2017b), Grace (2006, 2017), Plummer (2003, 2011, 2015) and Van den Berg (2016), among others, I wish to foreground how LGBTIQ+ academics and students, through acknowledging homogeneity (based on an assimilationist view), could inadvertently encourage an emphasis on heterogeneity, intersectionality and a critique of heteronormativity, as it relates to their unique expierences on South African university campuses. Thus, Grace (2017) argues that one may consequently be able to enage with both the repressive and enabling factors characterising the everyday lives of such individuals. This may encourage underlining the:

\footnotetext{
...complexities of [their] ways of being, belonging and acting in the world; interrogating normative understandings of sexuality and gender ... bringing heterosexist ... and homo/bi/ transphobic actions and language into question; and accounting for intersecting relational and cultural intricacies. (p. 46)
}

Epprecht (2005), Msibi (2013) and Reid (2013) declare that we must move beyond an uncritical adoption of Western views on sexuality, as the use of terms such as 'gay', 'lesbian' and 'queer' in a South African context has resulted in localised and contextually specific meanings for its users. In transending, what Halberstam (2005) terms 'perverse presentism', the constituents of universities (staff, students and management) may be able to address the concerns, challenges and unique experiences of sexual minorities to fully encourage a transformative context for all its sexual actors.

\section{Contextualising 'homosexualities' in academic contexts ${ }^{2}$}

Much has been written internationally on the lived experiences of self-identified gay and lesbian academics and students in higher education. On students, foci ranged from examples of homophobia directed towards them (Chang 2005; Fox \& Ore 2010; Sears 2009) and its implications, including increased levels of substance abuse and suicide (Cox et al. 2011; Rankin et al. 2010), to studies exploring the possibilities of potential interventions on behalf of the gay and/or lesbian students through safe spaces (Alvarez \& Schneider 2008; Beemyn \& Rankin 2016; Evans 2002). Studies on academics have contemplated the role of positive affirmations associated with openly gay and lesbian academics who could serve as credible sources on gender and sexual diversity (Grace 2006; Lambert et al. 2006); however, research has also commented on how academics, owing to fear of the implications of institutional homophobia, may remain closeted to safeguard their personal and professional selves (Dolan 1998; Slagle 2007). South African research yielded significant insights into the life-worlds of sexual minority learners in primary and secondary schools relating to experiences of homophobia (Butler et al. 2003; Francis 2017a, 2017b; Francis \& Reygan 2016; Kowen \& Davis 2006; McArthur 2015; Msibi 2012; Reygan \& Francis 2015) and the teaching and learning of themes on gender and sexual diversity (Francis 2017a, 2017b; Richardson 2004, 2008). Similar studies in higher education contexts have centred on the perceptions of and/or attitudes to homosexual students (De Wet, Rothmann \& Simmonds 2016; Johnson 2014; Msibi 2015; Rothmann \& Simmonds 2015); prejudice directed at these students on university campuses (Jagessar \& Msibi 2015; Matthyse 2017); and the influence of subtle heterosexism or sources of resilience associated with gay male academics and students (Rothmann 2016, 2017).

Jagessar and Msibi's (2015) work provides an insider's perspective of LGB $^{3}$ students' experiences of homophobia in university residences in KwaZulu-Natal. According to them, such an exploration '....is particularly important given the perceived positioning of universities as liberal spaces where diversity is tolerated, if not celebrated' (Jagessar \& Msibi 2015:64). Their findings emphasise how heterosexist policing exacerbate the prevalence of homophobic violence in residencies where sexual minorities deviate from heteronormative principles. This, as noted by Jagessar and Msibi (2015), accordingly recalls Atkinson and De Palma's (2009:18) argument that individuals continuously reinforce heterosexism '...through discourse'. Similar findings resulted from two studies on the attitudes of pre-service teachers at South African universities (De Wet et al. 2016; Rothmann \&

2.It is important to note the use of the plural in this regard. The reference to 'homosexualities' is indicative of the inherent diversity, plurality, localised and contestability associated with an individual's sexual identity, as opposed to the initially rigid categorisation of the proponents of the medical model, which posited same-sex attraction as homogeneous and pathological (cf. Fineman 2014; Plummer
1996, 2003, 2015).

3.The acronym LGB (lesbian, gay and bisexual) is retained based on its usage by Jagessar and Msibi (2015) in their article. 
Simmonds 2015), indicating how the participants exuded a heterosexist bias which rendered gay and lesbian issues and individuals as less significant in relation to heterosexuality and their heterosexual counterparts, respectively. Matthyse (2017) contends that, regardless of the inclusion of sexual orientation as one focal point in the 1997 White Paper on Higher Education, around which safer campus contexts needed to be created, the current White Paper for Post-school Education and Training (2014) has remained '...silent about the homophobia and transphobia which plagues South Africa and its institutions of higher learning' which recalls Balfour's (2016) and Msibi's (2013) argument that the transformational foci in higher education mainly emphasise the importance of race and sex, to the exclusion of or conflation with sexual orientation as it relates to calls for 'equality' (Matthyse 2017; Tucker 2010).

Notwithstanding these challenges and the necessity to conduct research to identify and redress the homophobia sexual minority academics and students face, Francis (2017b:14) believes that more should be done to emphasise the role of resilience and resistance by these individuals for, as he enquires, 'Are we to believe, based on the South African literature, that there is nothing good or positive about being LGBT in schools [or, one could add, universities]?'.

\section{Conceptualising 'resilience': From an ecological to a constructionist approach}

Initial studies on resilience, during the 1960s and 1970s, were informed by the work of proponents of developmental psychopathology. These studies centred on identifying '... patterns of positive adaptation during or following significant adversity or risk' (Masten et al. 2009:118) associated with a '...reduced vulnerability to environmental risk experiences' (Rutter 2006:2). Scholars regarded it necessary to understand the reasons why some individuals were typified as resilient, regardless of their struggles, as this could yield further findings to inform improved intervention and policy formulation for others facing similar adversities in a less resilient way (Masten 2001; Rutter 1979). These initial studies argued that to be regarded as resilient, two premises must be considered. Firstly, the fact that those typified as resilient are 'doing okay' in relation to others, based on the social (and arguably sexual) expectations in a particular context. Secondly, those social (and sexual) subjects who may be facing adversity could be inhibited in realising positive outcomes (Masten et al. 2009).

The ecological model resulted in reaction to developmental psychology. Bronfrenbrenner (1993) advocated an emphasis on the lived experiences of social actors, proposing that an individual's development, from its early stages and throughout his and/or her life course, depended on increasingly complex reciprocal interactional processes (i.e. proximal processes) between the individual and the surrounding persons, objects and symbols in society.
The form, power and content of these processes varied, according to him, based on the particular environment in which these interactions occurred. He believed that the proximal processes manifested more positive results impacting those circumstances where individuals found themselves in advantaged versus disadvantaged contexts (e.g. social stability, inclusion and support). Resilience as such was understood as representing positive behaviour, life satisfaction, greater self-esteem and self-confidence, happiness and the absence of undesirable behaviour (including mental illness or emotional distress, among others) (Grace 2015). By 'growing into resilience', Grace (2015) argues that an ecological process affords an increase in the '...capacities and abilities' of persons to deal with their everyday adversities. Informed by positivist paradigms that emphasise causal linkages and the predetermination of the health outcomes and status of individuals, Ungar (2004a:345) argues that '...proponents of an ecological model must necessarily choose arbitrary distinctions of what are to be accepted as evidences of healthy functioning'. Irrespective of the impressive contributions of this model, Ungar argues in favour of an additional emphasis on a constructionist approach to resilience. This, according to him, re-centres the point that the ecological model on its own may be unable to fully articulate the '...plurality of meanings individuals negotiate in their self-constructions as resilient' and may, by implication, not address the ambiguity associated with defining resilience as a social construct (Rutter 2007).

Aligned with this argument, recent studies on the process underline the necessity to consider the heterogeneity in people's experiences in terms of their resilience, particularly with regard to intersectionality across different cultures (Grace 2015; Matthyse 2017; Ungar 2004a, 2004b, 2011). Grace (2015:27), ascribing to this view, defines resilience as '...a multidimensional, non-linear, and fluid construct, [a] process....about capacity building, successful adaptation, and sustained competence in the face of stressors and risk taking; it involves building assets and mobilizing strategies to enhance signs of thriving' in individuals' everyday lives. The plurality of ways in which LGBTIQ+ individuals may access these sources of social resilience on university campuses is now contemplated.

\section{Enacting the social constructionist model as a source for 'hidden (or subversive) resilience' for lesbian, gay, bisexual, transgender, intersex, queer and/or questioning academics and students}

Much of a constructionist approach is likened to a postmodern or post-structuralist ontological basis, positing resilience as the '...outcome from negotiations between individuals and their environments for the resources to define themselves as healthy amidst conditions collectively viewed as adverse' (Ungar 2004a:342). Risk and adaptive factors are considered 
as '...chaotic, complex, relative, and contextual'. This allows an opportunity to view resilience such as to better comprehend how supposed vulnerable groups may '... discover and nurture resilience in ways often invisible' (Ungar 2004a:345) to others (i.e. through hidden resilience). Although such an approach may complement an ecological focus, the proponents of constructionism critique the latter approach for not foregrounding the subjective nature of how, by whom or as what resilience is defined. Consider Ungar's (2004a, 2004b) emphasis on the work of Kaplan (1999) in this regard. Kaplan argues that a limitation of the concept of resilience centres on the fact '...that it is tied to the normative judgments relating to particular outcomes', continuing:

\begin{abstract}
...it is possible that the socially defined desirable outcome may be subjectively defined as undesirable, while the socially defined undesirable outcome may be subjectively defined as desirable. From the subjective point of view, the individual may be manifesting resilience, while from the social point of view the individual may be manifesting vulnerability. (Kaplan 1999:31-32)
\end{abstract}

Supporting this definition raises two implications. Firstly, the importance of the relativistic nature of resilience based on the sexual actor's agency, and secondly, the permeable nature of a supposed rigid boundary and/or static binary logic (e.g. homosexuality vs. heterosexuality, an assimilationist vs. social constructionist paradigm), whether geographical and/ or structural or ideological.

Pertaining to the first point on agency, one should avoid an exclusive focus on pre-determined or arbitrary understandings of resilience. Ungar (2004b:79) therefore implores understanding the 'discursive empowerment' by the sexual actor, serving as a '...protective mechanism mediating risk factors, leading to self-definitions' of resilience by these marginalised groups. To Ungar (2004b:81), the process of resilience is the '...outcome of negotiations between individuals and their environments to maintain a self-definition as healthy' amid the surrounding hegemonic discourse. This relates to the significance of the reciprocal interaction between the individual and his or her social context; thus, one should necessarily override existing medicalised definitions of health and acknowledge the narratives of individuals regarding their preferred demarcation of 'problem behaviours' and success factors (Ungar 2004a:355). This may provide groups considered 'vulnerable' and 'marginal' (e.g. LGBTIQ+ academics and students) the inter-subjective agency to express their personal narratives which may posit them as happy and healthy (Watson \& Dispenza 2015). This notion underscores Msibi's (2012:518) critique of an exclusive focus on the negative experiences of 'queer learners', as such a view that may reinforce the idea that they are always powerless victims of heterosexism. Drawing on a 2013 article by Michael Schulman in the New York Times on gender and sexual diversity among American students, Fineman (2014:308) argues that these students create novel terminologies and categorisations of sexual and gender expression which, according to her, is an '...exciting example of how human beings can intentionally create nurturing social spaces in which to foster community and a sense of belonging', amid inherently diverse, fluid and plural understandings and enactment of these 'identities'.

In his study on 'troubling' heteronormative curricula in South African schools, Francis (2017b) provides an example of such agency by a gay learner. By acknowledging the centrality of heterosexist rhetoric, the learner, in a queerly subversive way, transgressed its demeaning effects through mocking those teachers who sought to belittle him in their classrooms. He recalled mimicking the 'ultra-alpha male' masculine walk of his homophobic teacher. He likened the teacher to 'The Hulk - but not like an incredibly good Hulk that fights bad guys. An ugly Hulk. A fat, evil, ugly Hulk' (Francis 2017b:104). In commenting on this, Francis provides an insightful example of how LGB learners are able to use their agency to critique the centrality of heteronormativity, rather than merely passively assimilating into a heterosexist context as victims of homophobia (Rothmann \& Simmonds 2015). Similar examples also emerge in the attempts of selfidentified homosexual academics to challenge heterosexist rhetoric and internalised homophobia, including Grace's (2006) emphasis on 'writing the queer self', Grace and Benson's (2000) 'autobiographical queer-life narrative', Maxey's (1999) 'critical reflexivity', Petrovic's (2002) 'radicalization of liberalism', Rothmann's (2016) reference to a 'deprofessionalisation' of the gay male academic identity and Warren's (1974) recommendation to engage in a 'reflective subjectivity'. Thus, LGBTIQ+ individuals access Rutter's (2007) 'steeling effects' through 'reflexiveness' to proactively construct their inter-subjective academic performance as the source for resilience and thriving through implicitly and explicitly critiquing heterosexism, rather than solely expierencing vulnerability and subjugation in the face of heteronormativity. These attempts echo Kumashiro's (2002) call in favour of anti-oppressive education pedagogies and policies, ${ }^{4}$ advocating an education approach which critiques the 'othering' of sexual minorities and promoting the transformation of existing hegemonic structures in education. Although laudable, he acknowledges that such an approach may potentially further essentialise and homogenise the experiences of sexual minorities and not necessarily result in proactive action by those who have been sensitised (Kumashiro 2002; Msibi 2015).

As such, although essential to create an awareness of the limitations associated with heteronormativity (Francis \& Brown 2017), one needs to move beyond an exclusive, restrictive view. To consider the likelihood for social resilience, university policy-makers, as noted, should acknowledge the uniquely fluid, plural and diverse nature of the supposed static category of 'the homosexual' (Foucault 1978) in an African and South African setting. This could elucidate the inherent heterogeneity of homosexual identities and practices. Although it is crucial to identify and challenge

4. Kumashiro (2002) differentiates between four processes social researchers could use to encourage the establishment of anti-oppressive education pedagogies, strategies and policies in education. These include 'education for the other', strategies and policies in education. These include 'education for the other',
'education about the other', 'education which is critical of othering' and 'education that changes society'. 
heterosexist and patriarchal inclinations, Lewis (2011:209) observes that researchers should '...extricate African sexuality from binaries that define heterosexuality as normatively African and homosexuality as deviant and Western' (Msibi 2013). The supposed 'un-African' nature and non-existence of homosexual practices on the African continent have been refuted by several studies that document the existence of same-sex practices as part of the African culture for centuries (Dlamini 2006; Mutua 2011). Consider, for example, Epprecht's (2005:142) critique of this invisibility of homosexuality. He argues that '...the history and current struggles of LGBTI people in Africa only remain hidden to those who actively desire not to see them'. In keeping with this point, Dlamini (2006:131) notes that Colonialism did not necessarily introduce the perceived 'secular' and 'un-African' vice of homosexuality to Africa, but rather its Christian condemnation thereof. One could thereby challenge reinforcing 'bitter knowledge' which, according to Msibi (2016:28), propounds prejudicial and stereotypical views of homosexuality. Aligned with the social constructionist view of resilience, Msibi (2015:392) acknowledges Kumashiro's (2002) argument to combine the various approaches to encourage social change in favour of the position of sexual minorities in education since '...oppression is multi-layered, multiple and situated'.

A monolithic view of a sexual subject's agency as only affording him and/or her social resilience should thus be avoided, given the diverse experiences that may result from enacting one's sexual orientation to potentially master one's resilience (Jagessar \& Msibi 2015). Resnick (2000), for example, poses the following question: '...To what extent and under what circumstances can protective factors be transplanted into the lives of ... people who have been socialized in a stressful climate of uncertainty and fear?'. Always consider, as argued by Grace (2015), the '...specific issues, challenges, or opportunities ... such as success in negotiating relationships' with others. Jagessar and Msibi's (2015:71) argument that the LGB residency students who participated in their study may internalise, normalise and even trivialise the heteronormative and homophobic institutional culture insofar as they justify the context as '...not [being] all that bad'. If viewed solely as agents, homosexual academics and students may be posited as the '...lone-hero[es]...overcoming [adversity] despite all odds', thus negating any emphasis on how collective action and/or structural inequality exacerbates heteronormative discrimination towards sexual minorities. Because of this, heterosexism may be reduced to an individual level (and how the 'lone' person redresses its effects), thus ignoring the role of specific institutions that codify racism, sexism and heterosexism in the overall campus culture, curriculum and discourse through unquestioned marginalisation and stigmatisation (Fineman 2014; Francis 2017b; Msibi 2012, 2013).

Pertaining to the permeability of geographical, structural and/ or ideological spaces, much has been written on the beneficial effects the creation of unique gay and lesbian subcultures or 'safe spaces' have for lesbian and gay individuals (Evans 2002). Others, however, have chronicled its role in possibly intensifying the minoritisation or homogenisation of sexual dissidents (Binnie \& Skeggs 2004), the exacerbation of the binary between the heterosexual and homosexual communities (Rink 2013) or the fallacious ideology of assured safety outside such communal spaces (Fox \& Ore 2010). Parallel to this thought, Ghaziani (2015), writing from an American perspective, attributes the changing social and political ideologies concerning the acceptance, accommodation and legal protections afforded to sexual minorities as a central reason why mainstream culture (which could include the university's campus culture in general) may also become an overarching 'inclusive ghetto' for all sexual actors, thus negating the necessity for separate and exclusive homosexual settings. Notwithstanding these arguments, recent scholarship on resilience implores an increased emphasis on the social context of vulnerable groups to understand their own unique indicators of resilient behaviour (Boyden \& Mann 2005; Reygan \& Francis 2015; Ungar et al. 2007). The work of Ungar et al. (2007:288) indicates that resilience cannot be understood as solely an individual's capacity to overcome adversity but also as the '...capacity of the individual's environment to provide access to health enhancing resources in culturally relevant ways'. This thought echoes similar contributions of theorists on gender and sexuality studies (Francis 2017b; Plummer 2003, 2015).

The inherent diversity associated with homosexual identities may likely counter the subjugation which homogenisation may present in, for example, a supposed 'safe space' for students (e.g. joining LGBTIQ+ student organisations) and academics (e.g. subject departments with mainly gay and lesbian staff or attempts at 'passing' as heterosexual) (Rothmann 2016, 2017). LGBTIQ+ individuals may thus access their agentic capacity to identify, choose and continuously reconstruct and deconstruct varied forms of their particular sexual orientation (e.g. lesbian, gay, bisexual, transgender, intersex, queer or questioning) (Van den Berg 2016) through a democratisation of both the physical and/or structural and ideological heteronormative habitus they occupy. Gorman-Murray's (2006:57) research on how Australian gay men '...fluidly use' their interactive capabilities to import their public gay sensibility into their homes, applies here. The study comments on the reciprocal interplay between establishing a communal context of belonging for gay men (e.g. in bars, clubs or safe spaces such as academic courses and/or academic and student organisations), whereby their identification with others (whether homogeneous or heterogeneous in terms of their gender and sexual identity) facilitate '...connections with others' and create '...personal happiness and self-acceptance' (Gorman-Murray 2006:60) in their personal lives, especially as it relates to secondary socialisation and democratisation of their sexuality. Emphasising the importance of intersectionality related to South African 'homosexualities' may provide a platform for academics and students to voice 
their experiences based on their varied racial, ethnic and gender identities. This, according to Francis (2017b:100), is imperative, because '...sexuality is never experienced in isolation from the whole subject'. He advocates a '....need to shift focus to consider the interplay and disruptions that inform how ... intersections have shaped [sexual subjects'] life histories and identities' (Francis 2017b:102). This argument recalls Simon's (1996:43-44) reference to how the construction of one's agentic personal sexual identity through intrapsychic scripting may be informed by your interpersonal interactions with others based on what is permitted within the larger cultural (e.g. heteronormative societal context) scenario.

By thus temporarily assimilating into an ethnic characterisation of homosexual homogeneity in external communal settings, these academics and students may access their agency and challenge critics on attaching a victimised label to them through the latter's supposed assimilation into what might be considered a heteronormative context, by becoming aware of their shared experiences, yet diverse inter-subjective life-worlds (Filiault \& Drummond 2008; Fineman 2014; Van den Berg 2016). I thus recall previous arguments that sexual diversity may only be acknowledged within an open, contestable and heterogeneous figuration of identity categories, rather than a complete negation of gender and sexual categorisation (cf. Plummer 2003; Rothmann 2012; Weeks 1986). By 'doing gay' (Dowsett 1996), sexual actors may problematise the supposed rigid boundary and static polarised binary logic between heterosexuality and homosexuality and underline its permeable nature (Rowe \& Dowsett 2008). This may weaken 'traditional modes of group think' and rather produce so-called 'flourishing sexualities'; thus, more 'sacral', 'individualized', 'reflexive' and 'informalized' sexualised performances which express an '...endless hunger for instant change...and selfreinvention' within the larger university context (Plummer 2015:172).

\section{Implications and concluding remarks}

In conclusion, the article seeks to consider the potential role of a social constructionist approach to resilience in encouraging the creation of a transformative university context for sexual minority academics and students. Whether this is done through an increased sensitisation of the general university staff and student constituency on matters relating to gender and sexual diversity through, among others, the provision of formalised policies to safeguard them, the introduction of optional or compulsory courses and/or modules on the topic in order to comment on the intersectionality associated with such identities or practices and dispel 'un-African' labels and establishing 'safer spaces' to redress the consequences of homophobia, context specificity and the agency of sexual actors should be foregrounded. In so doing, one avoids adopting an 'either/ or' approach (i.e. assimilationist vs. liberationist approach) to the position of sexual minorities, insofar as it foregrounds the continuous interplay between self-identified LGBTIQ+ academics and students' choices to assimilate, dis-assimilate and/or transgress communal contexts (e.g. safe spaces) for sexual minorities. Their individual choices may result in their need to either identify with others based on their sexual orientation; develop an appreciation for the inherently diverse, fluid and reflexively constructed interpretations of homosexual identities; or it may, along liberationist lines, indicate their outright critique of heteronormativity. Although the first two options risk the reinforcement of homonormativity within the parameters of an acceptable heteronormative view of the initial medicalised categorisation of homosexuality as simply pathological, assimilationist and homogeneous, it emphasises how these sexual subjects self-consciously enact their individual needs to access their social or hidden resilience - granted, within an existing heteronormative context.

In adopting a contextually specific and localised view of the needs of academics and students, university management and designated allies (e.g. course developers, lecturers and students) may not only be able to engage with the limitations associated with the structural challenges presented by a presumed heteronormative context but also consider the agentic possibilities sexual minorities may negotiate within such structures. I am cognisant of the fact that proponents of queer theory may critique such an approach, but one should, as argued by proponents of social constructionism, consider how these individuals establish a continuous dialogue with their social environment to assertively construct their sources for thriving resiliently.

\section{Acknowledgements Competing interests}

The author declares that he has no financial or personal relationships which may have inappropriately influenced him in writing this article.

\section{References}

Alvarez, S.D. \& Schneider, J., 2008, 'One college campus's need for a safe zone: A case study', Journal of Gender Studies 17(10), 71-74. https://doi.org/ 10.1080/09589230701838461

Atkinson, E. \& De Palma, R., 2009, 'Un-believing the matrix: queering consensual heteronormativity', Gender and Education 21(1), 17-29. https://doi.org/ 10.1080/09540250802213149

Balfour, R., 2016, 'The (in)visible gay in academic leadership: Implications for reimagining inclusion and transformation in South Africa', in D. Pillay, I. Naicker \& K. Pithouse-Morgan (eds.), Academic autoethnographies: Inside teaching in higher education, pp. 133-148, Sense, Boston, MA

Beemyn, G. \& Rankin, S.R., 2016, 'Creating a gender-inclusive campus', in Y.M. Migue \& S. Tobias (eds.), Trans-studies: The challenge to hetero/homo normativities, pp. 21-32, Rutgers University Press, New Brunswick, NJ.

Bhana, D., 2012, 'Understanding and addressing homophobia in schools: A view from teachers', South African Journal of Education 32, 307-318. https://doi.org/ $10.15700 /$ saje.v32n3a659

Bhana, D., 2014, "'Managing" the rights of gays and lesbians: Reflections from some South African secondary schools', Education, Citizenship and Social Justice 9(1) 67-80. https://doi.org/10.1177/1746197913497663

Binnie, J. \& Skeggs, B., 2004, 'Cosmopolitan knowledge and the production and consumption of sexualised space: Manchester's gay village', Sociological Review 52(1), 39-61. https://doi.org/10.1111/j.1467-954X.2004.00441.x

Boyden, J. \& Mann, G., 2005, 'Children's risk, resilience, and coping in extreme situations', in M. Ungar (ed.), Handbook for working with children and youth: Pathways to resilience across cultures and contexts, pp. 3-26, Sage, Thousand Oaks, CA. 
Bronfrenbrenner, U., 1993, 'Ecological models of human development', in N. Gauvain \& M. Cole (eds.), Readings on the development of children, 2nd edn., pp. 37-43, Freeman, New York.

Butler, A.H., Alpaslan, A.H., Strümpher, J. \& Astbury, G., 2003, 'Gay and lesbian youth experiences of homophobia in South African secondary education', Journal of Gay and Lesbian Issues in Education 1(2), 3-28. https://doi.org/10.1300/ J367v01n02 02

Cahill, A.J., 2011, Overcoming objectification: A carnal ethics, Routledge, New York.

Chang, Y., 2005, 'Through queers' eyes: Critical educational ethnography in quee studies', The Review of Education, Pedagogy, and Cultural Studies 27, 171-208. https://doi.org/10.1080/10714410590963857

Cox, N., Dewaele, A., Van Houtte, M. \& Vincke, J., 2011, 'Stress-related growth, coming out, and internalized homonegativity in lesbian, gay, and bisexual youth. An examination of stress-related growth within the minority stress model', Journal of Homosexuality 58(1), 117-137. https://doi.org/10.1080/00918369.2011.533631

De Vos, P., 2015, 'Mind the gap: Imagining new ways of struggling towards the emancipation of sexual minorities in Africa', Agenda 29(1), 39-53.

De Wet, A., Rothmann, J. \& Simmonds, S., 2016, 'Human rights: Protecting sexual minorities or reinforcing the boundaries of "the closet"?', The South African Review of Sociology 47(3), 85-109.

Dlamini, B., 2006, 'Homosexuality in the African context', Agenda 20(67), 128-136.

Dolan, J., 1998, 'Gay and lesbian professors: Out on campus', Academe 84(5), 40-45.

Dowsett, G.W., 1996, Practicing desire: Homosexual sex in the era of AIDS, Stanford University Press, Stanford, CA.

Epprecht, M., 2005, “'Hidden” histories of African homosexualities', Canadian Woman Studies 24(2/3), 138-144.

Evans, N.J., 2002, 'The impact of an LGBT safe zone project on campus climate', Qualitative Research 43, 522-539.

Filiault, S.M. \& Drummond, M.J.N., 2008, 'Athletes and body image: Interviews with gay sportsmen', Qualitative Research in Psychology 5(4), 311-333.

Fineman, M.A., 2014, 'Vulnerability, resilience, and LGBT youth', Temple Political \& Civil Rights Law Review 23(2), 307-329.

Foucault, M., 1978, The history of sexuality, vol. 1, Vintage, New York.

Fox, C.O. \& Ore, R.E., 2010, '(Un)covering normalized gender and race subjectivities in LGBT Safe Spaces', Feminist Studies 36(3), 629-649.

Francis, D., 2017a, 'Homophobia and sexuality diversity in South African schools: A review', Journal of LGBT Youth 14(4), 359-379. https://doi.org/10.1080.193616 53.2017.1326868

Francis, D., 2017b, Troubling the teaching and learning of gender and sexual diversity in South African education, Palgrave MacMillan, New York.

Francis, D. \& Brown, A., 2017, "“To correct, punish and praise" LRC leaders experiences and expressions of non-heterosexuality in Namibian schools', International Journal of Inclusive Education 21(12), 1-18. https://doi.org/10.1080/13603116.2 017.1336577

Francis, D. \& Reygan, F.C.G., 2016, 'Relationships, intimacy and desire in the lives of lesbian, gay and bisexual youth in South Africa', The South African Review of Sociology 47(3), 65-84. https://doi.org/10.1080/21528586.2016.1163290

Ghaziani, A., 2015, “'Gay enclaves face prospect of being passe”: How assimilation affects the spatial expressions of sexuality in the United States', International
Journal of Urban and Regional Research 39(4), 756-771. https://doi.org/ Journal of Urban and Regi
$10.1111 / 1468-2427.12209$

Gorman-Murray, A., 2006, 'Homeboys: Uses of home by gay Australian men', Socia and Cultural Geography 7(1), 53-69. https://doi.org/10.1080/14649360500452988

Grace, A.P., 2006, 'Writing the queer self: Using autobiography to mediate inclusive teacher education in Canada', Teaching and Teacher Education 22, 826-835. https://doi.org/10.1016/j.tate.2006.04.026

Grace, A.P., 2015, Growing into resilience: Sexual and gender minority youth in Canada, University Toronto Press, Toronto, ON.

Grace, A.P., 2017, 'Two good gay teachers: Pioneering advocate-practitioners confronting homophobia in schooling in British Columbia, Canada', Irish Educationa Studies 36(1), 43-56. https://doi.org/10.1080/03323315.2017.1289701

Grace, A.P. \& Benson, F.J., 2000, 'Using autobiographical queer life narratives of teachers to connect personal, political and pedagogical spaces', International Journal of Inclusive Education 4(2), 89-109. https://doi.org/10.1080/13 6031100284830

Halberstam, J., 2005, In a queer time and place: Transgender bodies, subcultural lives, New York University Press, New York.

Jackson, S., 2006, 'Interchanges: Gender, sexuality and heterosexuality: The complexity (and limits) of heteronormativity', Feminist Theory 7(1), 105-121. https://doi.org/10.1177/1464700106061462

Jagessar, V. \& Msibi, T., 2015, “'It's not that bad": Homophobia in the residences of a university in KwaZulu-Natal, Durban, South Africa', Agenda 29(1), 63-73. https:// doi.org/10.1080/10130950.2015.1022984

Johnson, B., 2014, 'The need to prepare future teachers to understand and combat homophobia in schools', South African Journal of Higher Education 28(4), $1249-1268$.

Kaplan, H.B., 1999, 'Toward an understanding of resilience: A critical review of definitions and models', in M.D. Glantz \& J.L. Johnson (eds.), Resilience and development: Positive life adaptations, pp. 17-84, Kluwer Academic/Plenum, New York.
Kitzinger, C., 2005, 'Heteronormativity in action: Reproducing the heterosexual nuclear family in afterhours medical calls', Social Problems 52(4), 477-498. nuclear family in afterhours medical call'
https://doi.org/10.1525/sp.2005.52.4.477

Kowen, D. \& Davis, J., 2006, 'Opaque young lives: Experiences of lesbian youth', Agenda 20(67), 80-92.

Kumashiro, K., 2002, Troubling education: Queer activism and anti-oppressive pedagogy, New York, Routledge Falmer.

Lambert, E.G., Ventura, L.A., Hall, D.E. \& Cluse-Tolar, T., 2006, 'College students' views on gay and lesbian issues', Journal of Homosexuality 50(4), 1-30. https://doi. org/10.1300/J082v50n04_01

Lewis, D., 2011, 'Representing African sexualities', in S. Tamale (ed.), African sexualities: A reader, pp. 199-216, Pambazuka Press, Cape Town.

Masten, A.S., 2001, 'Ordinary magic: Resilience processes in development', American Psychologist 56(3), 227-238. https://doi.org/10.1037/0003-066X.56.3.227

Masten, A.S., Cutuli, J.J., Herbers, J.E. \& Reed, M.J., 2009, 'Resilience in development', in S.J. Lopez \& R. Snyder (eds.), The Oxford handbook of positive psychology, pp. 117-131, Oxford University Press, Oxford.

Matthyse, G., 2017, 'Heteronormative higher education: Challenging the status quo through LGBTIQ awareness-raising', South African Journal of Higher Education 31(4), 112-126. https://doi.org/10.20853/31-4-890

Maxey, I., 1999, 'Beyond boundaries? Activism, academia, reflexivity and research', Area 31(3), 199-208. https://doi.org/10.1111/j.1475-4762.1999.tb00084.x

McArthur, T., 2015, 'Homophobic violence in a Northern Cape school: Learners confront the issue', Agenda 29(3), 1-7.

Msibi, T., 2009, 'Not crossing the line: Masculinities and homophobic violence in South Africa', Agenda 23(80), 50-54.

Msibi, T., 2012, “I'm used to it now": Experiences of homophobia among queer youth in South African township schools', Gender and Education 24(5), 515-533. https://doi.org/10.1080/09540253.2011.645021

Msibi, T., 2013, 'Denied love: Same-sex desire, agency and social oppression among African men who engage in same-sex relations', Agenda 27(2), 105-116.

Msibi, T., 2015, 'The teaching of sexual and gender diversity issues to pre-service teachers at the University of KwaZulu-Natal: Lessons from student exam responses', Alternation 12, 385-410.

Msibi, T., 2016, 'Bitter knowledge', in M.N. Rodriquez, J.W. Martino, C.J. Ingrey \& E. Brockenbrough (eds.), Critical concepts in queer studies and education: An
international guide for the twenty-first century, pp. 23-33, Palgrave MacMillan, internation

Mutua, M., 2011, 'Sexual orientation and human rights: Putting homophobia on trial', in S. Tamale (ed.), African sexualities: A reader, pp. 452-462, Pambazuka Press, in S. Tamale
Cape Town

Petrovic, J.E., 2002, 'Promoting democracy and overcoming heterosexism: And never the twain shall meet?', Sex Education 2(2), 145-154. https://doi. org/10.1080/14681810220144891

Plummer, K., 2003, 'Queers, bodies and postmodern sexualities: A note on revisiting the sexual in symbolic interactionism', Qualitative Sociology 26(4), 515-530. https://doi.org/10.1023/B:QUAS.0000005055.16811.1c

Plummer, K., 2011, 'Critical humanism and queer theory: Living with the tensions', in N.K. Denzin \& Y.S. Lincoln (eds.), The SAGE handbook of qualitative research, 4th edn., pp. 195-207, Sage, Thousand Oaks, CA.

Plummer, K., 2015, Cosmopolitan sexualities, Polity Press, Malden, MA.

Rankin, S.R., Weber, G., Blumenfeld, W. \& Frazer, S. 2010, 2010 state of higher education for lesbian, gay, bisexual, and transgender people, viewed 30
December 2013, from http://Igbtq.sdes.ucf.edu/docs/campuspride2010lgbtre portsummary.pdf.

Reid, G., 2013, How to be a real gay: Gay identities in small-town South Africa, University of KwaZulu-Natal Press, Scottsville, KY.

Resnick, P.D., 2000, 'Protective factors, resiliency, and healthy youth development', Adolescent Medicine 11(1), 157-164.

Reygan, F. \& Francis, D., 2015, 'Emotions and pedagogies of discomfort: Teachers' responses to sexual and gender diversity in the Free State, South Africa', Education as Change 19(1), 101-119. https://doi.org/10.1080/16823206.2014.943259

Richardson, E., 2004, '“A ripple in the pond": Challenging homophobia in a teacher education course', Education as Change 8, 146-163. https://doi.org/ 10.1080/16823200409487084

Richardson, E., 2008, 'Researching LGB youth in post-apartheid South Africa', Journal of Gay and Lesbian Issues in Education 3(2/3), 135-140.

Rink, B.M., 2013, 'Que(e)riyng Cape Town: Touring Africa's "gay capital” with the Pink Map', in J. Sarmento \& E. Brito-Henriques (eds.), Tourism in the global South: Heritages, identities and development, pp. 65-90, Centre for Geographical Heritages, identition,
Studies, Lisbon.

Rothmann, J., 2012, 'Sociology as bridge over troubled waters: Establishing a link between the principles of lesbian and gay studies and queer theory', The South African Review of Sociology 43(1), 41-61.

Rothmann, J., 2016, 'The (de)professionalisation of the gay male academic identity: Locking the closet door on South African university campuses', The South African Review of Sociology 47(4), 40-59.

Rothmann, J., 2017, 'The role of self-reflexivity on the part of gay male academics on South African university campuses', Acta Academica 49(1), 1-31.

Rothmann, J. \& Simmonds, S., 2015, “'Othering” non-normative sexualities through objectification of "the homosexual": Discursive discrimination by pre-service teachers', Agenda 103, 116-126. 
Rowe, M.S. \& Dowsett, G.W., 2008, 'Sex, love, friendship, belonging and place: Is there a role for "Gay Community" in HIV prevention today?', Culture, Health \& Sexuality 10(4), 329-344. https://doi.org/10.1080/13691050701843098

Rutter, M., 1979, 'Protective factors in children's responses to stress and disadvantage', in M.W. Kent \& J.E. Rolf (eds.), Primary prevention of psychopathology: Vol. 3. Social competence in children, pp. 49-74, University Press of New England, Hanover, $\mathrm{NH}$

Rutter, M., 2006, 'Implications of resilience concepts for scientific understanding', Annals of the New York Academy of Sciences 1094(1), 1-12. https://doi.org/ 10.1196/annals.1376.002

Rutter, M., 2007, 'Resilience, competence, and coping', Child Abuse and Neglect 31 205-209. https://doi.org/10.1016/j.chiabu.2007.02.001

Schippers, M., 2016, Beyond monogamy: Polyamory and the future of polyqueer sexualities, New York University Press, New York.

Sears, J.T., 2009, 'Interrogating the subject: Queering elementary education, 10 years on', Sex Education 9(2), 193-200. https://doi.org/10.1080/14681810902829653

Simon, W., 1996, Postmodern sexualities, Routledge, New York.

Slagle, R.A., 2007, 'Ferment in LGBT studies and queer theory', Journal of Homosexuality 52(1), 309-328.

Tong, R., 2008, Feminist thought: A more comprehensive introduction, 3rd edn., Westview Press, Boulder, CO.

Tucker, A., 2010, 'The "rights" (and "wrongs") of articulating race with sexuality: The conflicting nature of hegemonic legitimisation in South African queer politics', Social \& Cultural Geography 11(5), 433-449. https://doi.org/10.1080/14649365. 2010.488747
Ungar, M., 2004a, 'A constructionist discourse on resilience: Multiple contexts, multiple realities among at-risk children and youth', Youth and Society 35, 341-365. https://doi.org/10.1177/0044118X03257030

Ungar, M., 2004b, Nurturing hidden resilience in troubled youth, University of Toronto Press, Toronto, ON.

Ungar, M., 2011, 'Community resilience for youth and families: Facilitative physical and social capital in contexts of adversity', Children and Youth Services Review 33, 1742-1748. https://doi.org/10.1016/j.childyouth.2011.04.027

Ungar, M., Brown, M., Liebenberg, L., Othman, R., Kwong, W.M., Armstrong, M. et al. 2007, 'Unique pathways to resilience across cultures', Adolescence 42(166) 287-310.

Van den Berg, E., 2016, “The closet": A dangerous heteronormative space', The South African Review of Sociology 47(3), 25-44. https://doi.org/10.1080/215 28586.2016.1182445

Warren, C.A., 1974, Identity and community in the gay world, John Wiley, New York.

Watson, L.B. \& Dispenza, F., 2015, 'The Relationships among masculine appearance norm violations, childhood harassment for gender nonconformity, and body image concerns among sexual minority men', Journal of Gay \& Lesbian Mental Health 19(2), 145-164. https://doi.org/10.1080/19359705.2014. 993229

Wells, H. \& Polders, L., 2006, 'Anti-gay hate crimes in South Africa: Prevalence, reporting practices, and experiences of the police', Agenda 20(67), 20-28.

White Paper 3 on transformation in Higher Education, 1997, 'Government Gazette Vol. 386 No. 18207', 15th August. 